\title{
Mismatch negativity as a "translatable" brain marker toward early intervention for psychosis: a review
}

\author{
Tatsuya Nagai ${ }^{1}{ }^{*}$, Mariko Tada $^{1}$, Kenji Kirihara ${ }^{1}$, Tsuyoshi Araki $^{2}$, Seiichiro Jinde ${ }^{1}$ and Kiyoto Kasai ${ }^{1}$ \\ ${ }^{1}$ Department of Neuropsychiatry, Graduate School of Medicine, University of Tokyo, Tokyo, Japan \\ ${ }^{2}$ Department of Youth Mental Health, Graduate School of Medicine, University of Tokyo, Tokyo, Japan
}

\section{Edited by:}

Jun Soo Kwon, Seoul National

University College of Medicine, South

Korea

Reviewed by:

Vaibhav A. Diwadkar, Wayne State University School of Medicine, USA Christopher Schmidt, Pfizer Inc., USA KyungSoon Shin, NHN, South Korea

*Correspondence:

Tatsuya Nagai, Department of Neuropsychiatry, Graduate School of Medicine, University of Tokyo, 7-3-1 Hongo, Bunkyo-ku, Tokyo 113-8655, Japan

e-mail: t.nagai.md.psy@gmail.com
Recent reviews and meta-analyses suggest that reducing the duration of untreated psychosis leads to better symptomatic and functional outcome in patients with psychotic disorder. Early intervention attenuates the symptoms of individuals at clinical high-risk (HR) for psychosis and may delay or prevent their transition to psychosis. Identifying biological markers in the early stages of psychotic disorder is an important step toward elucidating the pathophysiology, improving prediction of the transition to psychosis, and introducing targeted early intervention for help-seeking individuals aiming for better outcome. Mismatch negativity (MMN) is a component of event-related potentials that reflects preattentive auditory sensory memory and is a promising biomarker candidate for schizophrenia. Reduced MMN amplitude is a robust finding in patients with chronic schizophrenia. Recent reports have shown that people in the early stages of psychotic disorder exhibit attenuation of MMN amplitude. MMN in response to duration deviants and in response to frequency deviants reveals different patterns of deficits. These findings suggest that MMN may be useful for identifying clinical stages of psychosis and for predicting the risk of development. MMN may also be a "translatable" biomarker since it reflects $\mathrm{N}$-methyl-d-aspartte receptor function, which plays a fundamental role in schizophrenia pathophysiology. Furthermore, MMN-like responses can be recorded in animals such as mice and rats. This article reviews MMN studies conducted on individuals with HR for psychosis, first-episode psychosis, recent-onset psychosis, and on animals. Based on the findings, the authors discuss the potential of MMN as a clinical biomarker for early intervention for help-seeking individuals in the early stages of psychotic disorder, and as a translatable neurophysiological marker for the preclinical assessment of pharmacological agents used in animal models that mimic early stages of the disorder.

Keywords: mismatch negativity, early intervention, first-episode psychosis, high-risk for psychosis, schizophrenia animal, translatable

\section{INTRODUCTION}

Recent reviews and meta-analyses suggest that patients with shorter duration of untreated psychosis (DUP) show better symptomatic and functional outcome (1-3). For example, early detection in first-episode psychosis (FEP) leads to a higher percentage of recovery over 10 years relative to usual-detection patients (4). Furthermore, early intervention in individuals with clinical highrisk (HR) for psychosis attenuates their symptoms and potentially delays or prevents their transition to psychosis (5-9). These findings suggest that early detection and intervention play a critical role in the improvement of functional outcome and even in the prevention of psychosis.

High-risk individuals can be identified using clinical criteria based on symptomatology (10); the rate of transition to psychosis is approximately $35 \%$ within $2-3$ years of follow-up (11), which is substantially higher than the incidence rate of psychosis in the general population. Higher sensitivity and specificity are required from the viewpoint of targeted early intervention.

For this reason, identifying biological markers in the early stages of psychotic disorders is an important step not only toward elucidating the underlying pathophysiology but also toward improving prediction of the transition to psychosis and introducing targeted early intervention to help-seeking individuals aiming for better outcome (12-14).

Auditory mismatch negativity (MMN) is a component of the event-related potential (ERP) and a promising biomarker candidate for psychotic disorders such as schizophrenia. A meta-analysis and several reviews of MMN in chronic schizophrenia (CSZ) are currently available (15-21). In this article, we focus on MMN in the early stages of psychotic disorders.

Mismatch negativity may also be a "translatable" biomarker because MMN reflects $N$-methyl-D-aspartte (NMDA) receptor function which plays a fundamental role in the pathophysiology of schizophrenia (22, 23), and MMN-like response can be recorded in animals including mice and rats (described later).

The following sections review MMN studies conducted on individuals in the early stages of psychosis and also on animals. In particular, the authors pay special attention to the finding that MMN in response to duration deviant stimuli and MMN in response to frequency deviant stimuli demonstrate different 
characteristics in the early stages of psychosis. Based on the results of these studies, the authors discuss the potential of MMN as a clinical biomarker for early intervention in help-seeking individuals and also as a translatable neurophysiological marker for the preclinical assessment of pharmacological agents tested in animal models that mimic early stages of the disorder.

\section{GENERAL BACKGROUND OF MMN}

Mismatch negativity is an ERP component elicited when an infrequent deviant stimulus occurs in a sequence of repetitive auditory stimuli. In an oddball paradigm, deviant stimuli differ from repetitive standard stimuli in one or more perceptual characteristics, including frequency, duration, intensity, location, spectrotemporal pattern, and phonemes $(16,19)$. MMN is even elicited under passive conditions when subjects ignore the stimuli. Thus, it is considered an index of preattentive auditory discrimination as well as a preattentive form of sensory memory (24).

Mismatch negativity relates to the difference wave obtained by subtracting the standard stimulus ERP from the deviant stimulus ERP (Figure 1) and usually peaks between 150 and $250 \mathrm{~ms}$ after presentation of the deviant stimulus (24). On electroencephalogram (EEG), maximal MMN responses are evident at frontocentral scalp recording sites, with phase reversal at mastoids.

\section{MMN IN CHRONIC SCHIZOPHRENIA}

Reduced MMN amplitude is one of the most robust findings in schizophrenia (25), and the mean effect size is approximately 0.99 (17). Given its high test-retest reliability (26), MMN has been proposed as a statistically reliable biomarker for schizophrenia.
Although many studies have used duration and/or frequency as deviant stimuli in auditory oddball paradigms, $\mathrm{MMN}$ in response to duration deviants $(\mathrm{dMMN})$ and in response to frequency deviants (fMMN) have different sensitivity. Michie et al. (15) examined both duration and frequency deviants in CSZ patients and demonstrated that amplitude reduction is larger in $\mathrm{dMMN}$ than in fMMN. Meta-analysis conducted on CSZ patients also revealed that the effect size of dMMN is larger than fMMN (17).

Mismatch negativity amplitude reduction reflects sensory network dysfunction in schizophrenia, as attention and motivation have little effect on MMN $(15,16,19,24)$. This provides an important advantage in clinical settings since patients are not required to perform an active task.

Previous studies have shown that antipsychotic medication has little effect on MMN (27-32); however, recently Zhou et al. (33) reported that antipsychotics such as aripiprazole improve MMN amplitude reduction in schizophrenia. Benzodiazepine has been reported to have no significant effect on MMN amplitude (34). Interestingly, it has been suggested that drugs acting at the NMDA receptor may have a significant effect on $\mathrm{MMN}$ in schizophrenia. Lavoie et al. (35) reported that $N$-acetyl-cysteine, a glutathione precursor that can potentiate the activity of NMDA receptors, increases $\mathrm{fMMN}$ amplitude in schizophrenia patients. However, further studies are needed to clarify whether other modulators of NMDA receptors, such as glycine transporter inhibitors and D-serine, can similarly enhance MMN amplitude in schizophrenia.

Correlations between MMN amplitude and clinical variables have been described in the literature. For example, it has been reported that the amplitude of $\mathrm{dMMN}$ is associated with social

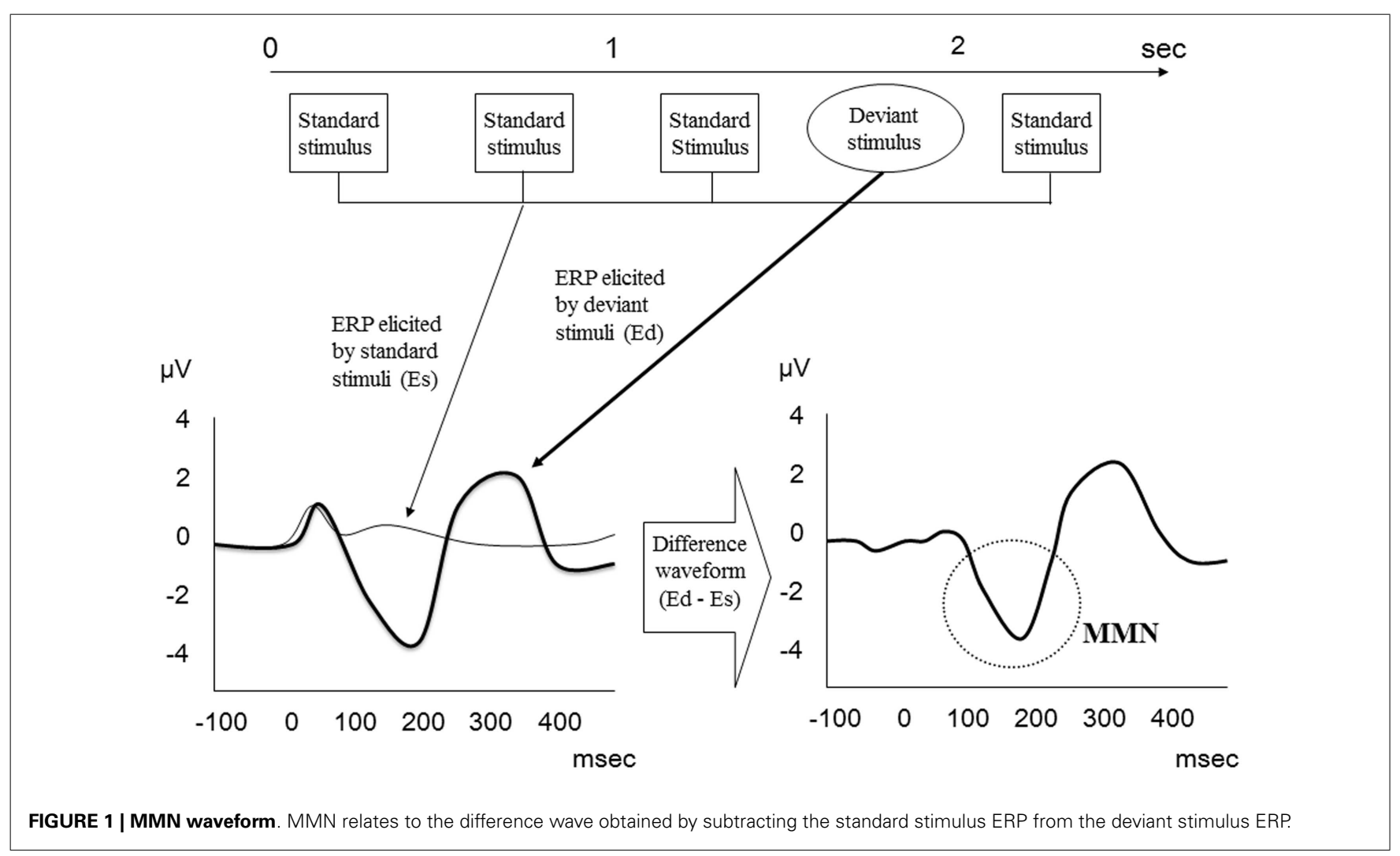


function (36), social cognition (37), and executive function (38) in CSZ, while phonetic MMN amplitude has been reported to be associated with verbal memory (39) and social skills acquisition (40). These findings indicate that MMN is a biologically and clinically significant index of schizophrenia.

\section{MMN IN PATIENTS WITH FIRST-EPISODE OR RECENT-ONSET PSYCHOSIS}

In recent years, the number of $\mathrm{MMN}$ reports on FEP and on recentonset psychosis (ROP) has grown (see Table 1). These studies suggest that $\mathrm{dMMN}$ and $\mathrm{fMMN}$ have different properties, as seen in CSZ.

All of these studies reported a significant attenuation of dMMN and $\mathrm{fMMN}$ amplitude in ROP, including recent-onset schizophrenia (RSZ), subjects compared to healthy controls (HC). Excluding the findings of Magno et al. (46), they also reported a significant attenuation of dMMN amplitude in FEP subjects compared to HC. In contrast, only Devrim-Ucok et al. (45) noted a significant reduction of fMMN amplitude in FEP subjects compared to HC (see Table 2). Salisbury et al. (54) reported that fMMN amplitude in first-episode schizophrenia (FES) patients became significantly smaller compared to HC approximately 1.5 years after onset of the illness, which correlated with a reduction in Heschl's gyrus volume. Thus, fMMN may reflect progression of the disease pathology, and $\mathrm{dMMN}$ amplitude may be attenuated before the onset of psychosis.

Within dMMN, the duration increment deviants (long duration) and the duration decrement deviants (short duration) may have different sensitivity. One study has demonstrated that a duration increment condition can discriminate between patients with CSZ and HC better than a duration decrement condition (16). While it is unclear whether this superiority of duration increment over duration decrement is true of FEP, it is interesting to note that all of the studies reporting a significantly attenuated dMMN in FEP or ROP utilized duration increments, whereas only Magno et al. (46) chose duration decrement and failed to show significantly decreased dMMN in FES (see Table 2). Atkinson et al.

Table 1 | Demographic data of previous studies of FEP or ROP.

\begin{tabular}{|c|c|c|c|c|c|c|c|c|}
\hline \multirow[t]{2}{*}{ Publication } & \multicolumn{3}{|c|}{ HC } & \multicolumn{4}{|c|}{ Patients } & \multirow[t]{2}{*}{ Comments } \\
\hline & $\mathbf{N}$ & $\mathbf{M} / \mathbf{F}$ & Age & $\mathbf{N}$ & $\mathbf{M} / \mathbf{F}$ & Age & DOI (y) & \\
\hline Javitt et al. (41) & 20 & $8 / 7$ & $36.3(9.5)$ & 13 (RSZ) & $10 / 3$ & $27.4(2.7)$ & & Most patients took medication \\
\hline Salisbury et al. (42) & 27 & $20 / 7$ & $24.2(4.3)$ & 21 (FES) & $18 / 3$ & $24.9(6.2)$ & & Most patients took medication \\
\hline Oades et al. (43) & 22 & $12 / 10$ & $17.6(0.4)$ & 28 (FES) & $21 / 7$ & $17.5(0.4)$ & & \\
\hline \multirow[t]{2}{*}{ Umbricht et al. (44) } & 39 & $26 / 13$ & $30.5(7.1)$ & 26 (FES) & $19 / 7$ & $23.9(5.5)$ & $0.05(0.1)$ & Most patients took SGA \\
\hline & & & & $26(\mathrm{RSZ})$ & $14 / 12$ & $30.3(6.7)$ & $3.4(1.5)$ & \\
\hline \multirow[t]{2}{*}{ Devrim-Ucok et al. (45) } & 34 & $19 / 15$ & $24.5(6.4)$ & 30 (FES acute) & $15 / 15$ & $22.1(5.7)$ & & Ten acute FES patients took medication \\
\hline & & & & 21 (FES post) & $12 / 9$ & $21.6(5.6)$ & & All post FES patients took medication \\
\hline Magno et al. (46) & 27 & $13 / 14$ & $38.0(12.9)$ & 12 (FES) & $9 / 3$ & $24.3(6.2)$ & & $\begin{array}{l}\text { Drug-naïve except for one patient taking } \\
\text { chlorpromazine }\end{array}$ \\
\hline Todd et al. (47) & 14 & $7 / 7$ & $24.0(11.7)$ & 14 (SZ short) & $8 / 6$ & $25.0(10.7)$ & $2.6(1.7)$ & Most patients took SGA \\
\hline Hermens et al. (48) & 17 & $7 / 9$ & $22.6(2.8)$ & 17 (FEP) & $12 / 5$ & $22.5(3.2)$ & & $\begin{array}{l}\text { Patients; } 1 \text { SZ, } 3 \text { SZA, } 5 \text { SZP, } 2 \text { BP, } 6 \text { MDD } \\
\text { Medication; } 15 \text { SGA, } 9 \text { AD, } 3 \text { mood } \\
\text { stabilizers }\end{array}$ \\
\hline Bodatsch et al. (49) & 67 & $35 / 32$ & $25.8(4.0)$ & 33 (FES) & $26 / 7$ & $26.0(6.5)$ & & \\
\hline Jahshan et al. (50) & 28 & $18 / 10$ & $19.2(3.4)$ & 31 (RSZ) & $25 / 6$ & $29.8(3.6)$ & $1.2(0.8)$ & Twenty-five patients took SGA \\
\hline \multirow[t]{2}{*}{ Kaur et al. (51) } & 18 & $11 / 7$ & $23.1(3.0)$ & 17 (FEPa) & $10 / 7$ & $22.8(4.6)$ & & Most patients took SGA \\
\hline & & & & 18 (FES) & $13 / 5$ & $22.2(3.5)$ & & \\
\hline Atkinson et al. (12) & 61 & $20 / 41$ & $19(3.5)$ & $11(\mathrm{FEP})$ & $5 / 6$ & $21(2.7)$ & & Eight patients took antipsychotics \\
\hline Higuchi et al. (52) & 20 & $14 / 6$ & $25.4(6.9)$ & 20 (FES) & $9 / 11$ & $27.2(7.3)$ & $0.65(0.5)$ & $\begin{array}{l}\text { Seven patients had no medication } \\
\text { More than half of the patients took SGA }\end{array}$ \\
\hline $\begin{array}{l}\text { Mondragon-Maya et al. } \\
\text { (53) }\end{array}$ & 24 & $14 / 10$ & $22.6(5.8)$ & 20 (FEP) & $13 / 7$ & $26.1(7.2)$ & & Antipsychotic naive \\
\hline
\end{tabular}

All values are shown as mean (standard deviation).

AD, antidepressant; BP, bipolar disorder; DOI, duration of illness; FEP, first-episode psychosis; FEPa, FEP with affective-spectrum; FES, first-episode schizophrenia; HC, healthy controls; MDD, major depressive disorder; ROP, recent-onset psychosis; RSZ, recent-onset schizophrenia; SGA, second-generation antipsychotics; SZ, schizophrenia; SZA, schizoaffective disorder; SZP, schizophreniform disorder.

FES acute means patients with FES on acute phase.

FES post means patients with FES on post-acute phase when their symptoms improved.

$S Z$ short means patients with schizophrenia who received their first diagnosis within 5 years. 
Table 2 | Oddball paradigm and results of previous studies of FEP or ROP.

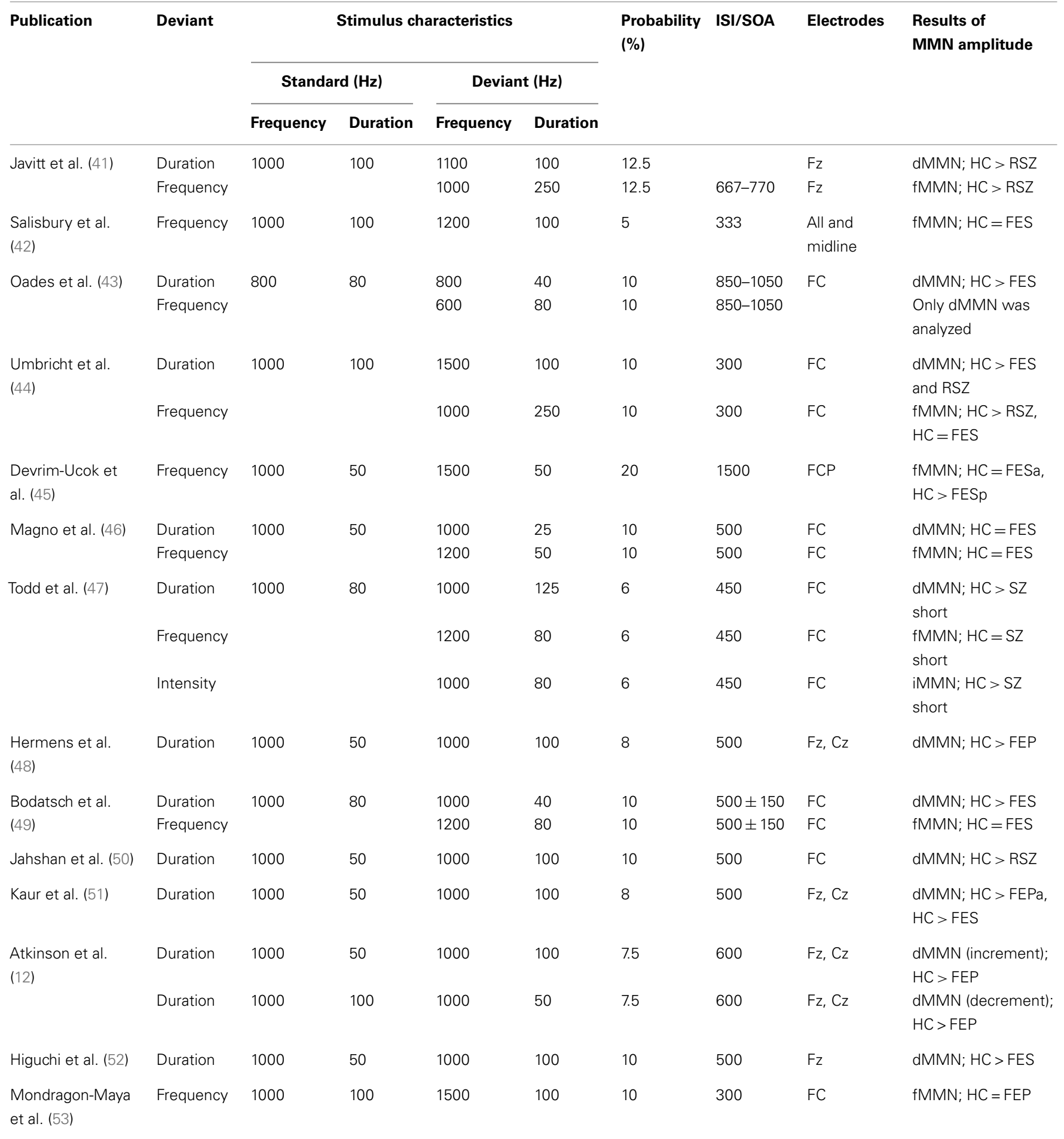

FC, frontocentral; FCP, frontocentral and parietal; HC, healthy controls; ISI, interstimulus interval; FEP, first-episode psychosis; FEPa, FEP with affective-spectrum; FES, first-episode schizophrenia; ROP, recent-onset psychosis; RSZ, recent-onset schizophrenia; SOA, stimulus onset asynchrony; SZ, schizophrenia.

FESa means patients with FES on acute phase.

FESp means patients with FES on post-acute phase when their symptoms improved.

$S Z$ short means patients with schizophrenia who received their first diagnosis within 5 years.

" $A>B$ " means that $A$ is significantly larger than $B$. " $A=B$ " means that $A$ and $B$ are not significantly different. 
(12) examined both duration increment and duration decrement and found that MMN to both duration deviants was reduced in FEP compared to HC. Discrepancies in the results of Magno et al. (46) and Atkinson et al. (12) may be due to differences in sample characteristics and the methods used to measure MMN.

The effect of medication on MMN has not been sufficiently investigated in FEP and ROP, although the finding that medication has little effect on MMN in CSZ lends to the possibility that a similar effect may be observed in FEP and ROP. However, further studies are needed to clarify this point.

Todd et al. (47) reported a significant positive correlation between fMMN amplitude and total score of the Schedule for Assessment of Positive Symptoms (SAPS), Delusions, Positive Formal Thought Disorder, and between iMMN amplitude and Hallucination, which indicates that higher symptom severities were associated with smaller MMN amplitude. In contrast, no correlation was found between dMMN amplitude and SAPS. Other studies have reported that no significant correlation exists between MMN amplitude and positive symptoms, as assessed by the Brief Psychiatric Rating Scale (BPRS) or the SAPS (12, 42, 43, 45).

As to negative symptoms, Oades et al. (43) reported that reduced mastoid dMMN is related to anergia and flat affect, as assessed by the Schedule for Assessment of Negative Symptoms (SANS). Umbricht et al. (44) demonstrated that a larger fMMN is associated with a higher SANS total score. However, other studies have described no significant correlation between MMN amplitude and negative symptoms, as assessed by BPRS or SANS (12, 42, 45, 47).

Besides positive and negative symptoms, MMN amplitude has also been significantly associated with anxious depression factor (42), Clinical Global Impression (CGI) (43), and cognitive functions $(48,51)$. On the other hand, it has been reported that MMN amplitude does not correlate with DUP (45), duration of illness (DOI) (46), or the Global Assessment of Functioning (GAF) (50).

Although a number of studies have noted a correlation between MMN amplitude and various clinical ratings in FEP as well as in CSZ, the findings are relatively inconsistent. Further studies with a large sample size are needed to confirm these correlations. In addition, a cross-sectional design study may not be appropriate since fMMN shows a progressive decrease after the onset of psychosis. Longitudinal studies will be more useful for investigating the association between $\mathrm{MMN}$ and clinical variables.

\section{MMN IN INDIVIDUALS AT CLINICAL HIGH-RISK FOR PSYCHOSIS}

Since Brockhaus-Dumke et al. (55) first examined MMN in individuals at clinical HR for psychosis, several MMN studies targeted at HR individuals have been reported (see Table 3 ). Regarding the criteria for HR, all of the studies utilized either the Bonn Scale for the Assessment of Basic Symptoms (BSABS) (56), Comprehensive Assessment of At-Risk Mental State (CAARMS) (57), or the Structured Interview for Prodromal Symptoms (SIPS) (58). CAARMS and SIPS include three subgroups for HR: attenuated psychotic symptoms (APS), brief limited intermittent psychotic episode (BLIP), and genetic risk and deterioration syndrome (GRD). BSABS describes basic symptoms (59).
The average observation period in these studies was approximately 7 months to 2 years, and the rate of conversion to psychosis was as follows: $13 \%[2 / 16 ;(60)], 40 \%[25 / 62 ;(49)], 8 \%$ $[2 / 26 ;(50)], 20 \%[6 / 30 ;(12)], 24 \%[10 / 41 ;(14)]$, and $24 \%$ $[4 / 17 ;(52)]$. Most of these rates were consistent with a previous study that assessed nearly $300 \mathrm{HR}$ help-seeking individuals whose conversion rate was approximately $35 \%$ within $2-3$ years of follow-up (11).

Most of these HR-focused studies examined dMMN (see Table 4), which might be because $\mathrm{dMMN}$ amplitude attenuation has a higher sensitivity than $\mathrm{PMMN}$ in FEP and in CSZ. Three studies examined fMMN $(49,53,55)$, and all of them failed to show reduced $\mathrm{PMMN}$ amplitude in $\mathrm{HR}$ compared to $\mathrm{HC}$, which is consistent with the previous findings that $\mathrm{MMN}$ reflects the progressive pathological process and that $\mathrm{PMMN}$ amplitude reduction is marked after the onset of psychosis (54). Significant reductions of dMMN amplitude were observed in most of the studies (12, 14, $50,60)$. However, in two studies, dMMN amplitude in HR individuals was not significantly smaller than that observed in $\mathrm{HC}$, and $\mathrm{dMMN}$ amplitude of converters to psychosis was significantly attenuated compared to HC $(49,52)$. Therefore, dMMN amplitude reduction seems evident as early as before the onset of full-blown psychosis.

Shin et al. (60) demonstrated that a smaller left dMMN magnetic counterpart dipole moment was associated with a larger positive symptom score, as measured by CAARMS. Other studies reporting on the association between $M M N$ amplitude and clinical symptoms, as assessed by BPRS, SAPS, or SANS, have not described any significant relations. Although an association between $\mathrm{dMMN}$ amplitude and GAF was reported in CSZ, two studies that examined GAF and MMN in HR failed to find a significant relation $(50,60)$. As to the relation between MMN and cognitive function, Higuchi et al. (52) showed that a larger dMMN amplitude was associated with a larger score of verbal fluency, as assessed by the Brief Assessment of Cognition in Schizophrenia (BACS). On the other hand, Brockhaus-Dumke et al. (55) reported no relation with multiple domains of cognitive function.

Finally, dMMN might have the ability to predict the conversion from HR to psychosis. Bodatsch et al. (49); Shaikh et al. (14), and Higuchi et al. (52) reported that converters to psychosis have significantly reduced $\mathrm{dMMN}$ amplitudes at presentation relative to non-converters. Furthermore, Bodatsch et al. (49) showed that dMMN amplitude could predict onset of psychosis; a prognostic score was calculated based on a Cox regression model and stratified into two risk classes, which revealed significantly different survival curves. Previous studies with a large cohort of individuals at clinical HR have demonstrated that clinical variables such as clinical symptoms and social dysfunction can predict the onset of psychosis in multivariate prediction algorithms $(11,61)$. Thus, dMMN may improve the predictive power for onset of psychosis in HR individuals.

\section{MMN IN ANIMALS}

MMN-like responses have also been reported in monkeys (62, $63)$, cats (64), guinea pigs (65), rats (66-75), and mice (76-78). Some studies have reported that evoked ERP responses are not necessarily $\mathrm{MMN}$ in rabbits (79), rats $(80,81)$, and mice (82). 
Table 3 | Demographic data of previous studies of HR.

\begin{tabular}{|c|c|c|c|c|c|c|c|c|c|}
\hline \multirow[t]{2}{*}{ Publication } & \multicolumn{3}{|c|}{$\mathrm{HC}$} & \multicolumn{5}{|c|}{ HR } & \multirow[t]{2}{*}{ Conversion to psychosis } \\
\hline & $\mathbf{N}$ & $\mathbf{M} / \mathbf{F}$ & Age & $\mathbf{N}$ & $\mathbf{M} / \mathbf{F}$ & Age & Criteria & Medication & \\
\hline Brockhaus-Dumke et al. (55) & 33 & $28 / 15$ & $24.5(3.3)$ & 43 & $29 / 14$ & $25.4(5.8)$ & BSABS & & \\
\hline Shin et al. (60) & 18 & $12 / 6$ & $22.1(2.0)$ & 16 & $10 / 6$ & $21.3(3.2)$ & CAARMS & 3 SGA & 2 Individuals \\
\hline Bodatsch et al. (49) & 67 & $35 / 32$ & $25.8(4.0)$ & 62 & $41 / 21$ & $24.8(6.0)$ & BSABS & None & 25 (23 SZ, 1 SZP, 1 DD) \\
\hline Jahshan et al. (50) & 28 & $18 / 10$ & $19.2(3.4)$ & 26 & $22 / 4$ & $21.9(3.7)$ & SIPS & 7 SGA & 2 (1 Manic, 1 SZ) \\
\hline Atkinson et al. (12) & 61 & $20 / 41$ & 19 (3.5) & 30 & $10 / 20$ & $17(3.6)$ & CAARMS & 7 RIS & 6 (3 SZA, 1 SZPa, 1 SZUn, 1 P-NOS) \\
\hline Shaikh et al. (14) & 50 & $25 / 25$ & $24.6(4.5)$ & 41 & $26 / 15$ & $24.7(4.7)$ & CAARMS & None & 10 (9 SZ, 1 Bipolar) \\
\hline Higuchi et al. (52) & 20 & $14 / 6$ & $25.4(6.9)$ & 17 & $4 / 13$ & $19.4(4.4)$ & CAARMS & $3 \mathrm{AP}$ & 4 (4 SZ) \\
\hline Mondragon-Maya et al. (53) & 24 & $14 / 10$ & $22.6(5.8)$ & 23 & $16 / 7$ & $20.1(5.4)$ & SIPS & None & \\
\hline
\end{tabular}

All values are shown as mean (standard deviation).

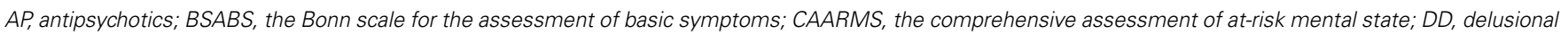

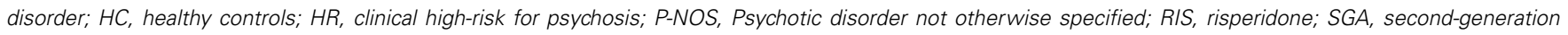
antipsychotics; SIPS, the structured interview for prodromal symptoms; SZ, schizophrenia; SZA, schizoaffective disorder; SZP, schizophreniform disorder; SZPa, schizophrenia paranoid type; SZUn, schizophrenia undifferentiated type.

Table 4 | Oddball paradigm and results of previous studies of HR.

\begin{tabular}{|c|c|c|c|c|c|c|c|c|c|c|}
\hline \multirow[t]{3}{*}{ Publication } & \multirow[t]{3}{*}{ Deviant } & \multicolumn{4}{|c|}{ Stimulus characteristics } & \multirow{3}{*}{$\begin{array}{l}\text { Probability } \\
(\%)\end{array}$} & \multirow[t]{3}{*}{ ISI/SOA } & \multirow[t]{3}{*}{ dB } & \multirow[t]{3}{*}{ Electrodes } & \multirow{3}{*}{$\begin{array}{l}\text { Results of } \\
\text { MMN amplitude }\end{array}$} \\
\hline & & \multicolumn{2}{|c|}{ Standard } & \multicolumn{2}{|c|}{ Deviant } & & & & & \\
\hline & & Frequency & Duration & Frequency & Duration & & & & & \\
\hline Brockhaus-Dumke et & Duration & 1000 & 80 & 1000 & 40 & 10 & $500 \pm 150$ & 75 & $\mathrm{FC}$ & $\mathrm{dMMN} ; \mathrm{HC}=\mathrm{HR}$ \\
\hline al. (55) & Frequency & & & 1200 & 80 & 10 & $500 \pm 150$ & 75 & $\mathrm{FC}$ & $\mathrm{fMMN} ; \mathrm{HC}=\mathrm{HR}$ \\
\hline Shin et al. (60) & Duration & 1000 & 50 & 1000 & 100 & 18.2 & 300 & 80 & & $\begin{array}{l}\text { dMMN Dipole } \\
\text { moment; } \mathrm{HC}>\mathrm{HR}\end{array}$ \\
\hline \multirow[t]{2}{*}{ Bodatsch et al. (49) } & Duration & 1000 & 80 & 1000 & 40 & 10 & $500 \pm 150$ & 75 & $\mathrm{FC}$ & $\begin{array}{l}\mathrm{dMMN} ; \mathrm{HC}=\mathrm{HR} \\
\mathrm{HC}>\mathrm{HR}-\mathrm{C}\end{array}$ \\
\hline & Frequency & & & 1200 & 80 & 10 & $500 \pm 150$ & 75 & $\mathrm{FC}$ & $f M M N ; H C=H R$ \\
\hline Jahshan et al. (50) & Duration & 1000 & 50 & 1000 & 100 & 10 & 500 & 85 & $\mathrm{FC}$ & $\mathrm{dMMN} ; \mathrm{HC}>\mathrm{HR}$ \\
\hline \multirow[t]{2}{*}{ Atkinson et al. (12) } & Duration & 1000 & 50 & 1000 & 100 & 7.5 & 600 & 70.5 & $\mathrm{Fz}, \mathrm{Cz}$ & $\begin{array}{l}\text { dMMN (Increment); } \\
\mathrm{HC}>\mathrm{HR}\end{array}$ \\
\hline & Duration & 1000 & 100 & 1000 & 50 & 7.5 & 600 & 70.5 & $\mathrm{Fz}, \mathrm{Cz}$ & $\begin{array}{l}\text { dMMN (Decrement); } \\
\mathrm{HC}>\mathrm{HR}\end{array}$ \\
\hline Shaikh et al. (14) & Duration & 1000 & 25 & 1000 & 50 & 15 & 300 & 80 & $\mathrm{Fz}, \mathrm{F3}, \mathrm{F} 4$ & $\mathrm{dMMN} ; \mathrm{HC}>\mathrm{HR}$ \\
\hline Higuchi et al. (52) & Duration & 1000 & 50 & 1000 & 100 & 10 & 500 & 60 & $\mathrm{Fz}$ & $\begin{array}{l}\mathrm{dMMN} ; \mathrm{HC}=H \mathrm{R} \\
\mathrm{HC}>\mathrm{HR}-\mathrm{C}\end{array}$ \\
\hline $\begin{array}{l}\text { Mondragon-Maya et } \\
\text { al. (53) }\end{array}$ & Frequency & 1000 & 100 & 1500 & 100 & 10 & 300 & & $\mathrm{FC}$ & $f M M N ; H C=H R$ \\
\hline
\end{tabular}

FC, frontocentral; HR, clinical high-risk for psychosis; HR-C, HR who converted to psychosis; ISI, interstimulus interval; SOA, stimulus onset asynchrony.

" $A>B$ " means that $A$ is significantly larger than $B$. " $A=B$ " means that $A$ and $B$ are not significantly different.

Previous studies using animal models have shown that antagonists of NMDA receptors reduce $\mathrm{MMN}(22,69,77)$. Given that NMDA receptors play an important role in the pathophysiology of schizophrenia, MMN may be a biomarker of dysfunctional NMDA receptors in this disease.
Ehrlichman et al. (78) reported that mutant mice heterozygous for neuregulin 1 showed reduced MMN. Since neuregulin 1 is one of the susceptibility genes for schizophrenia, MMN may be an intermediate phenotype that links genes to schizophrenia. These findings suggest that MMN may be 
useful for investigating molecular and cellular mechanisms of schizophrenia.

Recently, the neural adaptation hypothesis has been proposed as a general mechanism underlying $\mathrm{MMN}$, which challenges the traditional sensory memory hypothesis (83). The former hypothesis argues that repeated presentation of standard stimuli results in an adapted and attenuated response of neurons in the auditory cortex, whereas rare deviant stimuli evoke a larger response of neurons that are less adapted. Thus, MMN might reflect a stimulus-specific adaptation (SSA) rather than genuine deviance detection. A number of studies have attributed MMN-like responses to SSA in monkeys (84), cats (85), rats (86-91), and mice (92).

In order to resolve the controversy between the two hypotheses, several studies have adopted a many standards control paradigm to differentiate between SSA and genuine deviance detection. Some studies support the deviance detection theory $(73,74,88)$, while others do not (84). Although NMDA receptor antagonists have been shown to attenuate MMN amplitude $(22,69,77)$, Farley et al. (88) reported that SSA is not affected by NMDA receptor antagonism and suggested that the NMDA sensitivity reported for the MMN might occur at a mechanistic locus outside of SSA. In other words, the SSA hypothesis cannot explain MMN.

Recent modeling studies have proposed that MMN reflects prediction rather than adaptation $(93,94)$. These studies found that the prediction error hypothesis based on Bayesian inference can explain the property of MMN measured in human subjects. To our knowledge, however, there is no animal study that has investigated MMN based on the prediction error hypothesis. Since it has been found that NMDA receptor antagonists alter the process associated with prediction error (95), this hypothesis may provide a neurobiological mechanism that links NMDA receptors to MMN.

Overall, compared to human studies, there are more inconsistencies in the MMN studies carried out on animals. Even if MMN-like responses are evoked, the polarity and latency window of responses vary in rats (74). These inconsistencies could result from species or line differences, anesthesia effect, stimuli or paradigm differences, and different cortical layers targeted.

Improved protocols and replication of studies might overcome these variables, after which utilization of MMN as a translatable brain marker could be feasible for the preclinical assessment of pharmacological agents in animal models that mimic the early stage of psychotic disorders.

\section{CONCLUSION}

Mismatch negativity amplitude reduction is one of the most robust neurophysiological findings in schizophrenia patients.

\section{REFERENCES}

1. Marshall M, Lewis S, Lockwood A, Drake R, Jones P, Croudace T. Association between duration of untreated psychosis and outcome in cohorts of first-episode patients: a systematic review. Arch Gen Psy1001/archpsyc.62.9.975

2. Perkins DO, Gu H, Boteva K, Lieberman JA. Relationship chiatry (2005) 62:975-83. doi:10. between duration of untreated psychosis and outcome in firstepisode schizophrenia: a critical review and meta-analysis. Am J Psychiatry (2005) 162:1785-804. doi:10.1176/appi.ajp.162.10.1785

3. Farooq S, Large $M$, Nielssen $\mathrm{O}$, Waheed $\mathrm{W}$. The relationship between the duration of untreated psychosis and outcome in low-and-middle income
The amplitude of $\mathrm{dMMN}$ and that of $\mathrm{AMMN}$ have different characteristics. The fMMN amplitude may reflect the progressive pathological process and is attenuated after the onset of first-episode psychosis along with the reduction of Heschl's gyrus volume. The dMMN amplitude reduces before the onset of psychosis and may be a significant predictor of the conversion to psychosis. Since early interventions may delay or prevent the transition to psychosis, dMMN may be useful for identifying people who require early intervention. In contrast, fMMN may be a potential therapeutic target for preventing the disease progression. Although further longitudinal studies are needed, MMN may be an important step toward introducing targeted early intervention of help-seeking people aiming for a better outcome.

Animal studies have shed light on the underlying cellular mechanisms of MMN. If further studies could clarify these molecular and cellular mechanisms then MMN could potentially be used as a translatable brain marker for the preclinical assessment of pharmacological components designed to improve symptoms and cognitive and/or functional impairment in individuals in the early stages of psychosis.

\section{AUTHOR CONTRIBUTIONS}

Tatsuya Nagai wrote the first draft of the manuscript. Mariko Tada, Kenji Kirihara, Tsuyoshi Araki, and Kiyoto Kasai discussed and revised the manuscript.

\section{ACKNOWLEDGMENTS}

Part of this work was supported by the "Development of biomarker candidates for social behavior" project carried out under the Strategic Research Program for Brain Sciences by the MEXT. This work was also supported by JSPS KAKENHI (23791310 for Tsuyoshi Araki), the Global Center of Excellence (GCOE) Program "Comprehensive Center of Education and Research for Chemical Biology of the Diseases" (N. Yahata), SENSHIN Medical Research for Neurological and Psychiatric Disorders of NCNP (Tsuyoshi Araki), Takeda Science Foundation (Tsuyoshi Araki), JSPS Health and Labour Sciences Research Grants for Comprehensive Research on Disability, Health and Welfare (H22-seishin-ippan-015 to Kiyoto Kasai), Grant-in-Aid for Scientific research on Innovative Areas [Comprehensive Brain Science Network and Adolescent Mind and Self-Regulation (23118001 and 23118004) to Kiyoto Kasai] from the MEXT, and National Bioscience Database Center (NBDC) of Japan Science and Technology Agency (JST) to Kiyoto Kasai. Foundation (Kenji Kirihara), Intramural Research Grant (24-1)
5. McGorry PD, Yung AR,
Phillips LJ, Yuen HP, Francey
S, Cosgrave EM, et al. Randomized
controlled trial of interventions
designed to reduce the risk
of progression to first-episode
psychosis in a clinical sample
with subthreshold symptoms.
Arch Gen Psychiatry (2002)
59:921-8. doi:10.1001/archpsyc.
59.10.921 countries: a systematic review and meta analysis. Schizophr Res (2009) 109:15-23. doi:10.1016/j. schres.2009.01.008

4. Hegelstad WT, Larsen TK, Auestad B, Evensen J, Haahr U, Joa I, et al. Long-term follow-up of the TIPS early detection in psychosis study: effects on 10-year outcome. Am J Psychiatry (2012) 169:374-80. doi: 10.1176/appi.ajp.2011.11030459 
6. Morrison AP, French P, Parker $\mathrm{S}$, Roberts $\mathrm{M}$, Stevens H, Bentall RP, et al. Three-year followup of a randomized controlled trial of cognitive therapy for the prevention of psychosis in people at ultrahigh risk. Schizophr Bull (2007) 33:682-7. doi:10.1093/ schbul/sbl042

7. Amminger GP, Schafer MR, Papageorgiou K, Klier CM, Cotton SM, Harrigan SM, et al. Longchain omega-3 fatty acids for indicated prevention of psychotic disorders: a randomized, placebocontrolled trial. Arch Gen Psychiatry (2010) 67:146-54. doi:10.1001/ archgenpsychiatry.2009.192

8. Morrison AP, French P, Stewart SLK, Birchwood M, Fowler D, Gumley AI, et al. Early detection and intervention evaluation for people at risk of psychosis: multisite randomised controlled trial. BMJ (2012) 344:e2233-2233. doi: 10.1136/bmj.e2233

9. Stafford MR, Jackson H, MayoWilson E, Morrison AP, Kendall T. Early interventions to prevent psychosis: systematic review and meta-analysis. BMJ (2013) 346:f185. doi:10.1136/bmj.f185

10. Cannon TD, Cornblatt B, McGorry P. The empirical status of the ultra high-risk (prodromal) research paradigm. Schizophr Bull (2007) 33:661-4. doi:10.1093/schbul/sbm031

11. Cannon TD, Cadenhead K, Cornblatt B, Woods SW, Addington J, Walker E, et al. Prediction of psychosis in youth at high clinical risk: a multisite longitudinal study in North America. Arch Gen Psychiatry (2008) 65:28-37. doi:10.1001/ archgenpsychiatry.2007.3

12. Atkinson RJ, Michie PT, Schall U. Duration mismatch negativity and P3a in first-episode psychosis and individuals at ultrahigh risk of psychosis. Biol Psychiatry (2012) 71:98-104. doi:10.1016/ j.biopsych.2011.08.023

13. Belger A, Yucel GH, Donkers FC. In search of psychosis biomarkers in high-risk populations: is the mismatch negativity the one we've been waiting for? Biol Psychiatry (2012) 71:94-5. doi:10.1016/j. biopsych.2011.11.009

14. Shaikh M, Valmaggia L, Broome MR, Dutt A, Lappin J, Day F, et al. Reduced mismatch negativity predates the onset of psychosis. Schizophr Res (2012) 134:42-8. doi:10. 1016/j.schres.2011.09.022

15. Michie PT, Budd TW, Todd J, Rock D, Wichmann H, Box J, et al. Duration and frequency mismatch negativity in schizophrenia. Clin Neurophysiol (2000) 111:1054-65. doi:10.1016/S13882457(00)00275-3

16. Michie PT. What has MMN revealed about the auditory system in schizophrenia? Int J Psychophysiol (2001) 42:177-94. doi:10.1016/ S0167-8760(01)00166-0

17. Umbricht D, Krljes S. Mismatch negativity in schizophrenia: a meta-analysis. Schizophr Res (2005) 76:1-23. doi:10.1016/j. schres.2004.12.002

18. Turetsky BI, Calkins ME, Light GA, Olincy A, Radant AD, Swerdlow NR. Neurophysiological endophenotypes of schizophrenia: the viability of selected candidate measures. Schizophr Bull (2007) 33:69-94. doi:10.1093/schbul/sbl060

19. Naatanen R, Kahkonen S. Central auditory dysfunction in schizophrenia as revealed by the mismatch negativity (MMN) and its magnetic equivalent MMNm: a review. Int J Neuropsychopharmacol (2009) 12:125-35. doi:10.1017/ S1461145708009322

20. Rissling AJ, Makeig S, Braff DL, Light GA. Neurophysiologic markers of abnormal brain activity in schizophrenia. Curr Psychiatry Rep (2010) 12:572-8. doi:10.1007/ s11920-010-0149-z

21. Todd J, Michie PT, Schall U, Ward PB, Catts SV. Mismatch negativity $(\mathrm{MMN})$ reduction in schizophrenia-impaired prediction - error generation, estimation or salience? Int J Psychophysiol (2012) 83:222-31. doi:10.1016/j. ijpsycho.2011.10.003

22. Javitt DC, Steinschneider $M$, Schroeder CE, Arezzo JC. Role of cortical N-methyl-D-aspartate receptors in auditory sensory memory and mismatch negativity generation: implications for schizophrenia. Proc Natl Acad Sci U S A (1996) 93:11962-7. doi:10.1073/pnas.93.21.11962

23. Umbricht D, Schmid L, Koller R, Vollenweider FX, Hell D, Javitt DC. Ketamine-induced deficits in auditory and visual context-dependent processing in healthy volunteers: implications for models of cognitive deficits in schizophrenia. Arch Gen Psychiatry (2000) 57:1139-47. doi:10.1001/archpsyc. 57.12 .1139

24. Naatanen R, Paavilainen P, Rinne T, Alho K. The mismatch negativity (MMN) in basic research of central auditory processing: a review. Clin
Neurophysiol (2007) 118:2544-90. doi:10.1016/j.clinph.2007.04.026

25. Lawrie SM, Olabi B, Hall J, Mcintosh AM. Do we have any solid evidence of clinical utility about the pathophysiology of schizophrenia? World Psychiatry (2011) 10:19-31.

26. Light GA, Swerdlow NR, Rissling AJ, Radant A, Sugar CA, Sprock $\mathrm{J}$, et al. Characterization of neurophysiologic and neurocognitive biomarkers for use in genomic and clinical outcome studies of schizophrenia. PLoS One (2012) 7:e39434. doi:10.1371/ journal.pone.0039434

27. Schall U, Catts SV, Chaturvedi S, Liebert B, Redenbach J, Karayanidis F, et al. The effect of clozapine therapy on frontal lobe dysfunction in schizophrenia: neuropsychology and event-related potential measures. Int $J$ Neuropsychopharmacol (1998) 1:19-29. doi: 10.1017/S146114579800100X

28. Umbricht D, Javitt D, Novak G, Bates J, Pollack S, Lieberman J, et al. Effects of clozapine on auditory event-related potentials in schizophrenia. Biol Psychiatry (1998) 44:716-25. doi:10.1016/ S0006-3223(97)00524-6

29. Kasai K, Okazawa K, Nakagome K, Hiramatsu K, Hata A, Fukuda $\mathrm{M}$, et al. Mismatch negativity and $\mathrm{N} 2 \mathrm{~b}$ attenuation as an indicator for dysfunction of the preattentive and controlled processing for deviance detection in schizophrenia: a topographic eventrelated potential study. Schizophr Res (1999) 35:141-56. doi:10. 1016/S0920-9964(98)00116-9

30. Umbricht D, Javitt D, Novak G, Bates J, Pollack S, Lieberman J, et al. Effects of risperidone on auditory event-related potentials in schizophrenia. Int J Neuropsychopharmacol (1999) 2:299-304. doi:10.1017/ S1461145799001595

31. Korostenskaja M, Dapsys K, Siurkute A, Maciulis V, Ruksenas O, Kahkonen S. Effects of olanzapine on auditory P300 and mismatch negativity (MMN) in schizophrenia spectrum disorders. Prog Neuropsychopharmacol Biol Psychiatry (2005) 29:543-8. doi:10.1016/j.pnpbp.2005.01.019

32. Rissling AJ, Braff DL, Swerdlow NR, Hellemann G, Rassovsky Y, Sprock J, et al. Disentangling early sensory information processing deficits in schizophrenia. Clin Neurophysiol (2012) 123:1942-9. doi:10.1016/j.clinph.2012.02.079

33. Zhou Z, Zhu H, Chen L. Effect of aripiprazole on mismatch negativity (MMN) in schizophrenia. PLoS One (2013) 8:e52186. doi:10.1371/journal. pone.0052186

34. Kasai K, Yamada H, Kamio S, Nakagome K, Iwanami A, Fukuda M, et al. Do high or low doses of anxiolytics and hypnotics affect mismatch negativity in schizophrenic subjects? An EEG and MEG study. Clin Neurophysiol (2002) 113:141-50. doi:10.1016/ S1388-2457(01)00710-6

35. Lavoie S, Murray MM, Deppen P, Knyazeva MG, Berk M, Boulat $\mathrm{O}$, et al. Glutathione precursor, $\mathrm{N}$-acetyl-cysteine, improves mismatch negativity in schizophrenia patients. Neuropsychopharmacology (2008) 33:2187-99. doi:10. 1038/sj.npp.1301624

36. Light GA, Braff DL. Mismatch negativity deficits are associated with poor functioning in schizophrenia patients. Arch Gen Psychiatry (2005) 62:127-36. doi:10.1001/ archpsyc.62.2.127

37. Wynn JK, Sugar C, Horan WP, Kern R, Green MF. Mismatch negativity, social cognition, and functioning in schizophrenia patients. Biol Psychiatry (2010) 67:940-7. doi: 10.1016/j.biopsych.2009.11.024

38. Toyomaki A, Kusumi I, Matsuyama T, Kako Y, Ito K, Koyama T. Tone duration mismatch negativity deficits predict impairment of executive function in schizophrenia. Prog Neuropsychopharmacol Biol Psychiatry (2008) 32:95-9. doi:10.1016/j.pnpbp. 2007.07.020

39. Kawakubo Y, Kasai K, Kudo N, Rogers MA, Nakagome K, Itoh K, et al. Phonetic mismatch negativity predicts verbal memory deficits in schizophrenia. Neuroreport (2006) 17:1043-6. doi:10.1097/01. wnr.0000221828.10846.ba

40. Kawakubo Y, Kamio S, Nose T, Iwanami A, Nakagome K, Fukuda $\mathrm{M}$, et al. Phonetic mismatch negativity predicts social skills acquisition in schizophrenia. Psychiatry Res (2007) 152:261-5. doi:10. 1016/j.psychres.2006.02.010

41. Javitt DC, Shelley AM, Silipo G, Lieberman JA. Deficits in auditory and visual context-dependent processing in schizophrenia: defining the pattern. Arch Gen Psychiatry (2000) 57:1131-7. doi:10.1001/ archpsyc.57.12.1131

42. Salisbury DF, Shenton ME, Griggs $\mathrm{CB}$, Bonner-Jackson A, Mccarley RW. Mismatch negativity in chronic schizophrenia and firstepisode schizophrenia. Arch Gen 
Psychiatry (2002) 59:686-94. doi: 10.1001/archpsyc.59.8.686

43. Oades RD, Wild-Wall N, Juran SA, Sachsse J, Oknina LB, Ropcke B. Auditory change detection in schizophrenia: sources of activity, related neuropsychological function and symptoms in patients with a first episode in adolescence, and patients 14 years after an adolescent illness-onset. BMC Psychiatry (2006) 6:7. doi:10.1186/1471244X-6-7

44. Umbricht DS, Bates JA, Lieberman JA, Kane JM, Javitt DC. Electrophysiological indices of automatic and controlled auditory information processing in firstepisode, recent-onset and chronic schizophrenia. Biol Psychiatry (2006) 59:762-72. doi:10.1016/j. biopsych.2005.08.030

45. Devrim-Ucok M, Keskin-Ergen HY, Ucok A. Mismatch negativity at acute and post-acute phases of first-episode schizophrenia. Eur Arch Psychiatry Clin Neurosci (2008) 258:179-85. doi:10. 1007/s00406-007-0772-9

46. Magno E, Yeap S, Thakore JH, Garavan H, De Sanctis P, Foxe JJ. Are auditory-evoked frequency and duration mismatch negativity deficits endophenotypic for schizophrenia? High-density electrical mapping in clinically unaffected first-degree relatives and first-episode and chronic schizophrenia. Biol Psychiatry (2008) 64:385-91. doi:10.1016/j. biopsych.2008.03.019

47. Todd J, Michie PT, Schall U, Karayanidis F, Yabe H, Naatanen R. Deviant matters: duration, frequency, and intensity deviants reveal different patterns of mismatch negativity reduction in early and late schizophrenia. Biol Psychiatry (2008) 63:58-64. doi:10.1016/ j.biopsych.2007.02.016

48. Hermens DF, Ward PB, Hodge MA, Kaur M, Naismith SL, Hickie IB. Impaired MMN/P3a complex in first-episode psychosis: cognitive and psychosocial associations. Prog Neuropsychopharmacol Biol Psychiatry (2010) 34:822-9. doi: 10.1016/j.pnpbp.2010.03.019

49. Bodatsch M, Ruhrmann S, Wagner M, Muller R, Schultze-Lutter F, Frommann I, et al. Prediction of psychosis by mismatch negativity. Biol Psychiatry (2011) 69:959-66. doi:10.1016/j. biopsych.2010.09.057

50. Jahshan C, Cadenhead KS, Rissling AJ, Kirihara K, Braff DL, Light GA. Automatic sensory information processing abnormalities across the illness course of schizophrenia. Psychol Med (2012) 42:85-97. doi:10.1017/S0033291711001061

51. Kaur M, Battisti RA, Ward PB, Ahmed A, Hickie IB, Hermens DF. MMN/P3a deficits in first episode psychosis: comparing schizophrenia-spectrum and affective-spectrum subgroups. Schizophr Res (2011) 130:203-9. doi:10.1016/j.schres.2011.03.025

52. Higuchi $Y$, Sumiyoshi T, Seo T, Miyanishi T, Kawasaki Y, Suzuki M. Mismatch negativity and cognitive performance for the prediction of psychosis in subjects with at-risk mental state. PLoS One (2013) 8:e54080. doi:10.1371/ journal.pone. 0054080

53. Mondragon-Maya A, SolisVivanco R, Leon-Ortiz P, Rodriguez-Agudelo Y, YanezTellez G, Bernal-Hernandez J, et al. Reduced P3a amplitudes in antipsychotic naive first-episode psychosis patients and individuals at clinical high-risk for psychosis. J Psychiatr Res (2013) 47:755-61. doi:10.1016/j.jpsychires.2012.12. 017

54. Salisbury DF, Kuroki N, Kasai K, Shenton ME, Mccarley RW. Progressive and interrelated functional and structural evidence of post-onset brain reduction in schizophrenia. Arch Gen Psychiatry (2007) 64:521-9. doi:10.1001/ archpsyc.64.5.521

55. Brockhaus-Dumke A, Tendolkar I, Pukrop R, Schultze-Lutter F, Klosterkotter J, Ruhrmann S. Impaired mismatch negativity generation in prodromal subjects and patients with schizophrenia. Schizophr Res (2005) 73:297-310 doi:10.1016/j.schres.2004.05.016

56. Gross G, Huber G, Klosterkftter J, Linz M. Bonner Skala fqr die Beurteilung von Basissymptomen (BSABS; Bonn Scale for the Assessment of Basic Symptoms). Berlin: Springer (1987).

57. Yung AR, Yuen HP, McGorry PD, Phillips LJ, Kelly D, Dell'olio $\mathrm{M}$, et al. Mapping the onset of psychosis: the comprehensive assessment of at-risk mental states. Aust N Z J Psychia$\operatorname{try}$ (2005) 39:964-71. doi:10.1080/ j.1440-1614.2005.01714.x

58. Miller TJ, Mcglashan TH, Rosen JL, Cadenhead K, Cannon T, Ventura J, et al. Prodromal assessment with the structured interview for prodromal syndromes and the scale of prodromal symptoms: predictive validity, interrater reliability, and training to reliability. Schizophr Bull (2003) 29:703-15. doi:10.1093/ oxfordjournals.schbul.a007040

59. Fusar-Poli P, Borgwardt S Bechdolf A, Addington J, Riecher-Rossler A, SchultzeLutter F, et al. The psychosis high-risk state: a comprehensive state-of-the-art review. JAMA Psychiatry (2013) 70:107-20. doi: 10.1001/jamapsychiatry.2013.269

60. Shin KS, Kim JS, Kang DH, Koh Y, Choi JS, O'donnell BF, et al. Preattentive auditory processing in ultra-high-risk for schizophrenia with magnetoencephalography. Biol Psychiatry (2009) 65:1071-8. doi:10.1016/j.biopsych.2008.12. 024

61. Ruhrmann S, Schultze-Lutter F, Salokangas RK, Heinimaa M, Linszen D, Dingemans P, et al. Prediction of psychosis in adolescents and young adults at high risk: results from the prospective European prediction of psychosis study. Arch Gen Psychia$\operatorname{try}$ (2010) 67:241-51. doi:10.1001/ archgenpsychiatry.2009.206

62. Javitt DC, Schroeder CE, Steinschneider M, Arezzo JC, Vaughan HG Jr. Demonstration of mismatch negativity in the monkey. Electroencephalogr Clin Neurophysiol (1992) 83:87-90. doi:10.1016/ 0013-4694(92)90137-7

63. Javitt DC, Steinschneider M, Schroeder CE, Vaughan HG Jr, Arezzo JC. Detection of stimulus deviance within primate primary auditory cortex: intracortical mechanisms of mismatch negativity (MMN) generation. Brain Res (1994) 667:192-200. doi:10.1016/ 0006-8993(94)91496-6

64. Csepe V, Karmos G, Molnar M. Evoked potential correlates of stimulus deviance during wakefulness and sleep in cat - animal model of mismatch negativity. Electroencephalogr Clin Neurophysiol (1987) 66:571-8. doi:10.1016/ 0013-4694(87)90103-9

65. Kraus N, Mcgee T, Carrell T, King C, Littman T, Nicol T. Discrimination of speech-like contrasts in the auditory thalamus and cortex. $J$ Acoust Soc Am (1994) 96:2758-68. doi:10.1121/1.411282

66. Ruusuvirta T, Penttonen M, Korhonen T. Auditory cortical event-related potentials to pitch deviances in rats. Neurosci Lett (1998) 248:45-8. doi:10.1016/ S0304-3940(98)00330-9

67. Astikainen P, Ruusuvirta T, Wikgren J, Penttonen M.
Memory-based detection of rare sound feature combinations in anesthetized rats. Neuroreport (2006) 17:1561-4. doi:10.1097/01. wnr.0000233097.13032.7d

68. Ruusuvirta T, Koivisto K, Wikgren J, Astikainen P. Processing of melodic contours in urethaneanaesthetized rats. Eur J Neurosci (2007) 26:701-3. doi:10.1111/j. 1460-9568.2007.05687.x

69. Tikhonravov D, Neuvonen T, Pertovaara A, Savioja K, Ruusuvirta T, Naatanen R, et al. Effects of an NMDA-receptor antagonist MK801 on an MMN-like response recorded in anesthetized rats. Brain Res (2008) 1203:97-102. doi: 10.1016/j.brainres.2008.02.006

70. Roger C, Hasbroucq T, Rabat A, Vidal F, Burle B. Neurophysics of temporal discrimination in the rat: a mismatch negativity study. Psychophysiology (2009) 46:1028-32. doi:10.1111/j. 1469-8986.2009.00840.x

71. Tikhonravov D, Neuvonen T, Pertovaara A, Savioja K, Ruusuvirta T, Naatanen R, et al. Doserelated effects of memantine on a mismatch negativity-like response in anesthetized rats. Neuroscience (2010) 167:1175-82. doi:10.1016/ j.neuroscience.2010.03.014

72. Ahmed M, Mallo T, Leppanen $\mathrm{PH}$, Hamalainen J, Ayravainen L, Ruusuvirta T, et al. Mismatch brain response to speech sound changes in rats. Front Psychol (2011) 2:283. doi:10.3389/fpsyg.2011.00283

73. Astikainen P, Stefanics G, Nokia M, Lipponen A, Cong F, Penttonen $\mathrm{M}$, et al. Memory-based mismatch response to frequency changes in rats. PLoS One (2011) 6:e24208. doi:10.1371/journal. pone. 0024208

74. Nakamura T, Michie PT, Fulham WR, Todd J, Budd TW, Schall U, et al. Epidural auditory event-related potentials in the rat to frequency and duration deviants: evidence of mismatch negativity? Front Psychol (2011) 2:367. doi:10.3389/fpsyg. 2011.00367

75. Ruusuvirta T, Lipponen A, Pellinen E, Penttonen M, Astikainen P. Auditory cortical and hippocampal-system mismatch responses to duration deviants in urethane-anesthetized rats. PLoS One (2013) 8:e54624. doi:10.1371/ journal.pone.0054624

76. Umbricht D, Vyssotki D, Latanov A, Nitsch R, Lipp HP. Deviancerelated electrophysiological activity in mice: is there mismatch negativity in mice? Clin Neurophysiol 
(2005) 116:353-63. doi:10.1016/j. clinph.2004.08.015

77. Ehrlichman RS, Maxwell CR, Majumdar S, Siegel SJ. Devianceelicited changes in event-related potentials are attenuated by ketamine in mice. J Cogn Neurosci (2008) 20:1403-14. doi:10.1162/ jocn.2008.20097

78. Ehrlichman RS, Luminais SN, White SL, Rudnick ND, Ma N, Dow HC, et al. Neuregulin 1 transgenic mice display reduced mismatch negativity, contextual fear conditioning and social interactions. Brain Res (2009) 1294: 116-27. doi:10.1016/j.brainres. 2009.07.065

79. Ruusuvirta T, Korhonen T, Arikoski J, Kivirikko K. ERPs to pitch changes: a result of reduced responses to standard tones in rabbits. Neuroreport (1996) 7:413-6. doi:10.1097/00001756199601310-00009

80. Lazar R, Metherate R. Spectral interactions, but no mismatch negativity, in auditory cortex of anesthetized rat. Hear Res (2003) 181:51-6. doi:10.1016/ S0378-5955(03)00166-7

81. Sambeth A, Maes JH, Van Luijtelaar G, Molenkamp IB, Jongsma ML, Van Rijn CM. Auditory eventrelated potentials in humans and rats: effects of task manipulation. Psychophysiology (2003) 40: 60-8. doi:10.1111/1469-8986. 00007

82. Ehlers CL, Somes C. Long latency event-related potentials in mice: effects of stimulus characteristics and strain. Brain Res (2002) 957:117-28. doi:10.1016/S00068993(02)03612-0

83. May PJ, Tiitinen H. Mismatch negativity $(\mathrm{MMN})$, the devianceelicited auditory deflection, explained. Psychophysiology (2010) 47:66-122. doi:10.1111/j. 1469-8986.2009.00856.x

84. Fishman YI, Steinschneider M. Searching for the mismatch negativity in primary auditory cortex of the awake monkey: deviance detection or stimulus specific adaptation? J Neurosci (2012) 32:15747-58. doi:10.1523/ JNEUROSCI.2835-12.2012

85. Ulanovsky N, Las L, Farkas D, Nelken I. Multiple time scales of adaptation in auditory cortex neurons. J Neurosci (2004) 24:10440-53. doi:10.1523/ JNEUROSCI.1905-04.2004

86. Malmierca MS, Cristaudo S, Perez-Gonzalez D, Covey E. Stimulus-specific adaptation in the inferior colliculus of the anesthetized rat. J Neurosci (2009) 29:5483-93. doi:10.1523/ JNEUROSCI.4153-08.2009

87. Behrens W, Bauerle P, Kossl M, Gaese BH. Correlating stimulusspecific adaptation of cortical neurons and local field potentials in the awake rat. J Neurosci (2009) 29:13837-49. doi:10.1523/ JNEUROSCI.3475-09.2009

88. Farley BJ, Quirk MC, Doherty JJ, Christian EP. Stimulus-specific adaptation in auditory cortex is an NMDA-independent process distinct from the sensory novelty encoded by the mismatch negativity. J Neurosci (2010) 30:16475-84 doi:10.1523/JNEUROSCI.279310.2010

89. Taaseh N, Yaron A, Nelken I Stimulus-specific adaptation and deviance detection in the rat auditory cortex. PLoS One (2011) 6:e23369. doi:10.1371/journal. pone.0023369

90. Zhao L, Liu Y, Shen L, Feng L, Hong B. Stimulus-specific adaptation and its dynamics in the inferior colliculus of rat Neuroscience (2011) 181:163-74. doi:10.1016/j.neuroscience.2011. 01.060

91. Antunes FM, Nelken I, Covey E Malmierca MS. Stimulus-specific adaptation in the auditory thalamus of the anesthetized rat. PLoS One (2010) 5:e14071. doi:10.1371/ journal.pone.0014071

92. Anderson LA, Christianson GB, Linden JF. Stimulusspecific adaptation occurs in the auditory thalamus. I Neurosci (2009) 29:7359-63. doi:10.1523/ JNEUROSCI.0793-09.2009

93. Wacongne C, Changeux JP, Dehaene S. A neuronal model of predictive coding accounting for the mismatch negativity. J Neurosci (2012) 32:3665-78. doi:10.1523/ JNEUROSCI.5003-11.2012

94. Lieder F, Daunizeau J, Garrido MI, Friston KJ, Stephan KE. Modelling trial-by-trial changes in the mismatch negativity. PLoS Comput
Biol (2013) 9:e1002911. doi:10. 1371/journal.pcbi.1002911

95. Corlett PR, Honey GD, Krystal JH, Fletcher PC. Glutamatergic model psychoses: prediction error, learning, and inference. Neuropsychopharmacology (2011) 36:294-315. doi:10.1038/npp.2010.163

Conflict of Interest Statement: The authors declare that the research was conducted in the absence of any commercial or financial relationships that could be construed as a potential conflict of interest.

Received: 22 April 2013; accepted: 09 September 2013; published online: 23 September 2013

Citation: Nagai T, Tada M, Kirihara K, Araki T, Jinde S and Kasai K (2013) Mismatch negativity as a "translatable" brain marker toward early intervention for psychosis: a review. Front. Psychiatry 4:115. doi: 10.3389/fpsyt.2013.00115

This article was submitted to Schizophrenia, a section of the journal Frontiers in Psychiatry.

Copyright $(2013$ Nagai, Tada, Kirihara, Araki, Jinde and Kasai. This is an openaccess article distributed under the terms of the Creative Commons Attribution License (CC BY). The use, distribution or reproduction in other forums is permitted, provided the original author (s) or licensor are credited and that the original publication in this journal is cited, in accordance with accepted academic practice. No use, distribution or reproduction is permitted which does not comply with these terms. 